\title{
Pensamento computacional como auxílio para estimular a noção espacial das crianças do Ensino Fundamental
}

\author{
Anielly Isabel Duarte da Silva ${ }^{1}$, Cintia Reis de Oliveira ${ }^{1}$, Karina de Sena Pegado \\ Ilnicki', Charles Andryê Galvão Madeira', André Maurício Cunha Campos ${ }^{1}$ \\ ${ }^{1}$ Instituto Metrópole Digital (IMD) - Universidade Federal do Rio Grande do Norte \\ (UFRN) - CEP: 59.078-970 - Natal - RN - Brasil \\ anielly_duarte@hotmail.com, cintia.reiseifce.edu.br, \\ kasena@hotmāil.com, charles@imd.ufrn.br, andreddimap.ufrn.br
}

\begin{abstract}
Given the reality in articulating technology and education, using them to develop skills and competences, and the diagnosis regarding the difficulty of students of the 1st year of elementary school in the spatial localization of their body and surroundings, this article aims to use methodologies that provide activities related to creativity, logical reasoning, peer socialization and laterality. For this, it is proposed the use of concepts and practices of computational thinking, through unplugged tasks and digital activities with the Code Hour platform, observing the positive results regarding the spatial notion of the children participating in the study. .
\end{abstract}

Resumo. Diante da realidade em articular tecnologia e educação, usando-os para desenvolver habilidades e competências, e do diagnóstico a respeito da dificuldade dos alunos do $1^{\circ}$ ano do Ensino Fundamental na localização espacial do seu corpo e do entorno, o referido artigo tem como objetivo utilizar metodologias que proporcionem atividades relacionadas à criatividade, raciocínio lógico, socialização entre pares e lateralidade. Para isso, propõe-se a utilização de conceitos e práticas do pensamento computacional, por meio de tarefas desplugadas e atividades digitais com a plataforma da Hora do Código, observando-se os resultados positivos no que diz respeito a noção espacial das crianças participantes do estudo.

\section{Introdução}

As tecnologias digitais da informação e comunicação (TDICs) trazem para o contexto educacional novos debates e propostas metodológicas, que discutem a necessidade de inovar na sala de aula diante da crescente evolução da sociedade em que os nossos alunos estão inseridos refletindo diretamente no fazer pedagógico. De acordo com Almeida e Valente (2014) a escola deve trabalhar com a diversidade de processos de aprender, comunicar e construir conhecimentos e para isso deve-se utilizar de instrumentos contemporâneos como as TDICs. Assim, o perfil de aluno que tem-se nos dias atuais apresenta a necessidade da articulação entre tecnologia e educação urgentemente, pois a era digital é inata ao seu desenvolvimento, cabendo a escola como instituição formativa, buscar práticas que desenvolvam o domínio de habilidades necessárias para aprender no século XXI.

Cabe à escola inclusiva trabalhar com a diversidade de processos de aprender, comunicar e construir conhecimentos com o uso dos instrumentos culturais presentes na sociedade contemporânea, entre os quais as TDIC, bem como desenvolver nos estudantes o olhar crítico sobre a mídia, considerando-se as diferentes culturas, valores, 
VIII Congresso Brasileiro de Informática na Educação (CBIE 2019)

Anais dos Workshops do VIII Congresso Brasileiro de Informática na Educação (WCBIE 2019)

significados e sistemas de relações das quais são oriundos seus alunos, assim como os distintos letramentos que abrem novas perspectivas para a expressão do pensamento, a interação social e a aprendizagem

Dentro deste quadro atual, a BNCC (Base Nacional Comum Curricular) que apresenta-se como um documento de caráter normativo sobre os conteúdos a serem ensinados durante a Educação Básica, relata como uma das Competências Gerais "compreender, utilizar e criar tecnologias digitais de informação e comunicação, de forma crítica, significativa, reflexiva e ética nas diversas práticas sociais (incluindo as escolares), para se comunicar, acessar, disseminar informações, produzir conhecimentos, resolver problemas e exercer protagonismo e autoria na vida pessoal e coletiva". O documento tem como propósito desenvolver as habilidades e as competências que os alunos necessitam dentro dos conteúdos curriculares, a partir da preocupação em inserir a tecnologia no ambiente escolar, visto a importância em acompanhar o desenvolvimento da sociedade e fazer parte desse processo no qual a criança, como principal sujeito, deve participar de uma forma ativa.

Os desafios que os novos modelos de ensino apresentam a fim de acompanhar e integrar o uso da tecnologia ao ambiente escolar dependem muito da realidade de cada escola, bem como da forma que cada professor se adequa a esse novo modelo. O CIEB ${ }^{1}$ (Centro de Inovação para a Educação Brasileira) defende o uso das Tecnologias da Informação e da Comunicação (TICs) como forma de realizar uma transformação sistêmica nos processos de aprendizagem. Assim, um dos fatores essenciais do uso das tecnologias na educação é que, concomitantemente ao uso, surgem metodologias e estratégias que buscam inovar o interior da escola, atualizando-a e colocando-a à altura do seu tempo.

Desde o nascimento e durante a fase de desenvolvimento, a criança vem aperfeiçoando e estabilizando seus movimentos. Segundo Bee (1984, p. 95), "altura, músculo, ossos, sistema nervoso e hormônios passam por mudanças. Todas essas alterações atuam juntas para afetar como a criança e o adolescente podem usar o seu corpo, um processo denominado desenvolvimento motor". Desse modo, a criança necessita de estímulos para desenvolver habilidades pertinentes a cada fase de sua vida. Dentro da referida pesquisa, o ensino de programação se apresenta, além do conhecimento a novos conceitos, como uma estratégia utilizada para aguçar as habilidades de localização espacial e lateralidade além de outros conhecimentos que podem ser trabalhados transversalmente.

Diante do exposto, o referente artigo busca ressaltar a importância do ensino do uso da tecnologia no Ensino Fundamental, séries iniciais, agregando o conhecimento do pensamento computacional e apontando relações com as competências gerais e habilidades expressas na BNCC. Segundo Wing (2016, p. 02), pensamento computacional é uma habilidade fundamental para todos, não somente para cientistas da computação. À leitura, escrita e aritmética, deveríamos incluir pensamento computacional na habilidade analítica de todas as crianças.

Buscando articular essa estratégia, foi iniciado um estudo para estabelecer o eixo e o conceito a ser trabalhado em uma turma de primeiro ano do Ensino Fundamental séries iniciais, da Rede Pública de Ensino, do Município de Natal/RN. Diante da dificuldade do grupo em se localizar espacialmente e se posicionar

${ }^{1} \mathrm{http} / /$ cieb.net.br/ 
VIII Congresso Brasileiro de Informática na Educação (CBIE 2019)

Anais dos Workshops do VIII Congresso Brasileiro de Informática na Educação (WCBIE 2019)

lateralmente com o sentido direita e esquerda, foi proveniente decidir pelo eixo de Pensamento Computacional no conceito de Algoritmo, para isso, utilizou-se como fundamentação, o site do CIEB, que tem como missão promover a cultura de inovação na Educação Pública, o qual relaciona os conceitos da Ciência da Computação as habilidades referidas na BNCC.

Portanto, a presente proposta visa ensinar as práticas de localização espacial e lateralidade, aliando conceitos do pensamento computacional por meio de atividades desplugadas e digitais com objetivo de desenvolver o raciocínio e a sequência lógica de passos de forma interdisciplinar e contextualizada. Além disso, a atividade propõe a socialização e o trabalho em equipe das crianças participantes, contribuindo não só para resolução de um problema específico, mas para a formação humanística e social.

O artigo está estruturado em cinco seções, distribuídas da seguinte forma: 1 . Introdução, apresenta os aspectos relevantes sobre pensamento computacional e competências da BNCC (2018); 2. Trabalhos relacionados, apresenta estudos em semelhança ao tema; 3. Metodologia, traz a descrição metodológica da pesquisa; 4. Aplicação e Resultados da sequência didática apontando os caminhos percorridos como forma de resultado da prática pedagógica e 5. Considerações finais sobre a aplicação e utilidade do ensino do pensamento computacional durante o Ensino Fundamental.

\section{Trabalhos relacionados}

Oportunizar as crianças a vivenciarem o pensamento computacional é uma necessidade atual, visto a era digital a qual pertencem. Dessa forma, apresenta-se trabalhos que contemplam pesquisas e experimentos com atividades de pensamento computacional dentro do contexto pedagógico.

Gasparini et al (2018) relata uma proposta de atividade com o objetivo de verificar como os estudantes iriam aplicar a lógica para a resolução da situaçãoproblema e comparar os resultados da atividade individual com o trabalho em equipe. Cada estudante recebeu um mapa náutico e a atividade consistiu em encontrar um caminho utilizando a quantidade mínima de retângulos, recolhendo 10 objetos "perdidos" pelo pirata e estabelecer a melhor rota (traçando uma linha), desviando de diversos obstáculos. A atividade aconteceu individualmente e em grupo. Ao realizar a atividade percebeu-se que os estudantes não refletiram primeiramente, já ligando logo os retângulos para encontrar os objetos, o que ocasionou muitos caminhos desconexos.

Goulart et al (2018) apresenta uma abordagem para a construção de um processo de ensino-aprendizagem gamificado, visando a inclusão do ensino de programação e algoritmos no Ensino Fundamental através da realização de atividades lúdicas gamificadas usando recursos informacionais e ferramentas educacionais diferenciadas e inovadoras. Inicialmente foram selecionados conteúdos de matemática de acordo com os documentos e currículo da escola e escolhidos três jogos que abordam a criptografia e uso de sequências lógicas com o objetivo de desenvolver o raciocínio lógico e matemático alinhado com as habilidades e competências advindas do uso de computadores. Com os resultados socializa-se que o aumento gradativo das notas dos estudantes é notório, o que é um resultado significativo considerando que o projeto visava reforço pedagógico, especialmente nas disciplinas das Ciências Exatas.

Souza el al (2017), relatam a experiência de discentes do curso de licenciatura em Computação com o objetivo de Auxiliar os alunos do $8^{\circ}$ e $9^{\circ}$ ano na Olimpíada Brasileira de Matemática das Escolas Públicas (OBMEP) e introduzir a computação na 
VIII Congresso Brasileiro de Informática na Educação (CBIE 2019)

Anais dos Workshops do VIII Congresso Brasileiro de Informática na Educação (WCBIE 2019)

Educação Básica. Após três semanas de aulas específicas, elaborou-se um teste inicial e um teste final para as duas turmas, contendo os mesmos conteúdos e os mesmos critérios de avaliação. Em uma turma, pode-se notar que houve aumento da nota em Língua Portuguesa, onde os alunos formularam a interpretação de texto, definiram lógica e sua importância e conceituaram algoritmo de programação. Foi possível observar com a dinâmica que é possível contextualizar o conceito de lógica durante as aulas de disciplinas obrigatórias como português e matemática.

Dentro do que foi encontrado durante a realização da busca por pesquisas que trabalhassem o pensamento computacional, verificou-se a importância de associar esse conceito de pensamento computacional dentro das escolas já no início do Ensino Fundamental, dessa forma, as aulas podem ficar mais dinâmicas e diferenciadas para os alunos. Por ser um assunto bastante debatido por educadores e na sociedade em geral, existe um amplo campo de pesquisa referente a esse tema e os trabalhos relacionados elencados, bem como, outras pesquisas na área amparam e norteiam a pesquisa em questão.

\section{Metodologia do trabalho}

A criação da proposta baseia-se inicialmente em uma conversa diagnóstica com a turma, a fim de detectar o conhecimento e a usabilidade sobre aspectos de jogos digitais e analógicos. Este passo torna-se importante para entender qual o contexto em que a turma está inserida e traçar estratégias para a melhor condução da prática. Segundo Luckesi (1992) a avaliação diagnóstica tem como finalidade informar o professor sobre o grau de conhecimentos e habilidades de seus alunos, antes de começar o processo de ensino-aprendizagem.

Em seguida, para o ensino dos conceitos de algoritmo e sequência lógica de passo, optou-se por utilizar elementos de mecânica de jogos através de uma abordagem desplugada, na qual foi apresentado o jogo da Turma da Mônica, disponível no site pensamento computacional ${ }^{2}$, este site apresenta jogos para serem utilizados através de uma licença que permite a opção de remixar, adaptar e criar a partir do original para fins não comerciais, desde que atribuam o devido crédito e que licencie as novas criações sob termos idênticos, seguindo os critérios do autor Brackmann, 2017.

O jogo da turma da Mônica é formado por um tabuleiro de malha quadriculada e peças que correspondem aos personagens da história como é exibido na figura 1. $\mathrm{O}$ objetivo do jogo é exercitar prioritariamente os conceitos de Reconhecimento de padrões e de algoritmos por meio da busca por trajetos entre dois pontos, aprendendo uma forma de escrever resumidamente os mesmos comandos e relacionar os movimentos utilizados no jogo com os conteúdos de sala de aula que trabalha a lateralidade e a noção espacial.

http://www.computacional.com.br/ 


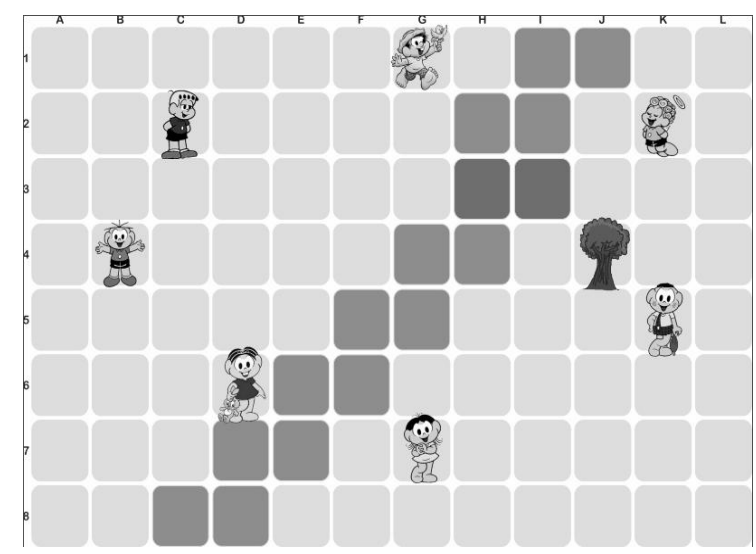

Figura 1. Tabuleiro do Jogo Turma da Mônica

As regras do jogo se apresentam da seguinte forma: o objetivo é encontrar o menor caminho entre um ponto inicial (personagem 1) e um ponto final (personagem 2); Deve-se registrar a rota escolhida através de flechas (instruções: avance, vire à direita, vire à esquerda, conforme apresentadas na Figura 4, indicando como o personagem deve se deslocar pelo tabuleiro. Como obstáculos, o personagem não pode atravessar a árvore durante o seu caminho. O rio não pode ser atravessado em qualquer ponto, mas somente quando houver uma ponte.

Por último, os estudantes poderão praticar os conceitos de algoritmos no jogo online Angry Birds do site Code.org, que caracteriza-se como uma ferramenta online de ensino de pensamento computacional e raciocínio lógico, na atividade os estudantes terão a oportunidade de trabalhar o conceitos estudados em uma plataforma digital e perceber a relação do conteúdo com a forma de funcionamento do computador.

Tabela 1. Prototipação da metodologia

\begin{tabular}{|l|l|l|}
\hline \multicolumn{1}{|c|}{ Etapa } & \multicolumn{1}{|c|}{ Método } & \multicolumn{1}{c|}{ Objetivo } \\
\hline $\begin{array}{l}\text { Levantamento de aspectos } \\
\text { diagnósticos }\end{array}$ & $\begin{array}{l}\text { Perguntas do tipo: "Qual o seu } \\
\text { jogo preferido?" e "Qual a a } \\
\text { diferença entre jogos físicos e enhecer qual o contato dos } \\
\text { jogos online?" }\end{array}$ & $\begin{array}{l}\text { Constigar a curiosidade sobre } \\
\text { alunos com os jogos digitais e } \\
\text { instiono funciona um jogo digital. } \\
\text { coma }\end{array}$ \\
\hline $\begin{array}{l}\text { Introdução sobre o conceito de } \\
\text { Algoritmo }\end{array}$ & $\begin{array}{l}\text { Exemplos de atividades que } \\
\text { requerem passos bem definidos, } \\
\text { como uma receita de bolo. }\end{array}$ & $\begin{array}{l}\text { Introduzir nas crianças a noção } \\
\text { de sequência lógica de passos. }\end{array}$ \\
\hline $\begin{array}{l}\text { Realização de atividade } \\
\text { Desplugada. }\end{array}$ & $\begin{array}{l}\text { Uso do jogo de Tabuleiro Turma } \\
\text { da Mônica, inicialmente com a } \\
\text { implementação original e em } \\
\text { seguida com o uso em um } \\
\text { tabuleiro humano. }\end{array}$ & $\begin{array}{l}\text { Fortalecer os conceitos que } \\
\text { passos, lateralidade e noção } \\
\text { espacial. }\end{array}$ \\
\hline Realização da jogo online & $\begin{array}{l}\text { Jogo Angry Birds do site } \\
\text { Code.org }\end{array}$ & $\begin{array}{l}\text { Fazer a relação entre os } \\
\text { conceitos estudados e área de } \\
\text { Ciências da Computação }\end{array}$ \\
\hline
\end{tabular}


VIII Congresso Brasileiro de Informática na Educação (CBIE 2019)

Anais dos Workshops do VIII Congresso Brasileiro de Informática na Educação (WCBIE 2019)

\section{Aplicação e Resultados}

A Escola Municipal de Natal, campo de execução escolhido para a referida pesquisa, conta com duas turmas do primeiro ano das séries iniciais, com um total de vinte alunos cada, na faixa etária entre seis e sete anos de idade. No dia da aplicação da aula prática a participação foi de vinte e nove alunos concentrados todos em uma única sala, contando com a presença de três professoras e duas auxiliares de sala. Durante as orientações da atividade os alunos mantiveram-se atentos e criativos diante da proposta, apresentando interesse por atividades que estimulem a criatividade e o movimento do corpo, portanto, as instruções da atividade foram de fácil entendimento de todos os participantes.

Para iniciar a atividade com a turma, foi formado um círculo com as crianças, e iniciada uma conversa prévia a fim de identificar suas preferências e tipos de jogos de acordo com a figura 2. Perguntas como por exemplo "Qual seu jogo preferido?" foram utilizadas. A maioria das crianças respondeu demonstrando interesse por futebol, somente uma se mostrou interessada no jogo digital Free fire. Assim, dentro da realidade social em que as crianças estão inseridas, ficou entendido que poucas delas possuem contato com os jogos digitais. Relacionando a resposta dos alunos, eles foram questionados se sabiam a diferença entre jogo de futebol e jogos online. Para as crianças é bem definido que um jogo físico possui um objeto no qual podem tocar, que no caso do futebol é a bola. Em relação aos jogos digitais, algumas crianças relataram que podem jogar no celular ou tablet.

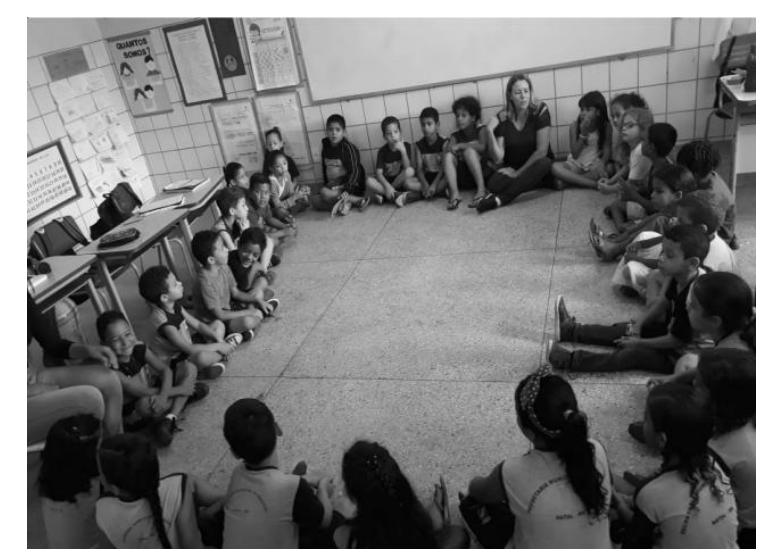

Figura 2. Roda com as crianças

Durante a roda de conversa foi observado que as crianças diferenciam o jogo digital do jogo físico, mas não sabem como ocorre o processo dentro do computador. Assim, iniciou-se uma conversa sobre o que é algoritmo, como ideia de sequenciar passos, para deixar a atividade mais próxima e compreensível às crianças. Foram realizados exemplos comparando a ideia de uma receita de bolo, que necessita de uma sequência lógica de passos para ser executada com sucesso.

Em seguida, com placas de: "avance", "gire à direita" e "gire à esquerda", foi iniciada uma explanação com um professor sendo o robô e o outro o programador. Para isso, as crianças escolheram como desafio, pegar uma garrafa em cima de uma mesa específica, no qual o robô deveria realizar a tarefa com a ajuda do programador que apresentava os comandos a serem executados conforme a figura 3. 
VIII Congresso Brasileiro de Informática na Educação (CBIE 2019)

Anais dos Workshops do VIII Congresso Brasileiro de Informática na Educação (WCBIE 2019)

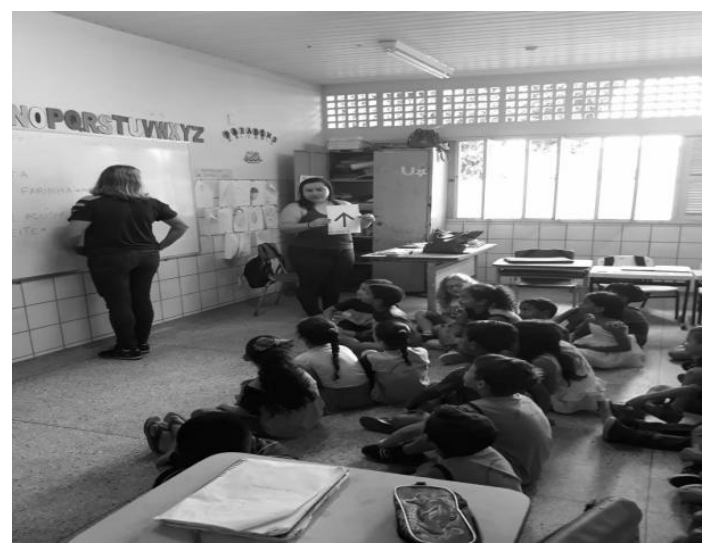

Figura 3. Explanação do robô e do programador

Posteriormente, os alunos tiveram a oportunidade de praticar as instruções repassadas, iniciando com o tabuleiro da turma da mônica impresso de acordo com a Figura 1, em seguida com a utilização do jogo de tabuleiro, com o próprio corpo como peças, formado por uma malha quadriculada no chão e máscaras dos personagens do jogo. A cada rodada foram escolhidos três participantes, dois para fazer a representação dos personagens e um programador a exemplo da figura 4 . O programador teria que resolver a situação problema entre os personagens utilizando o menor caminho, ou seja, poucos comandos, e os personagens só poderiam avançar ou girar para a direita ou esquerda seguindo o código do programador.

Durante a atividade foi possível trabalhar a lateralidade das crianças, bem como a noção espacial, tornando assim a aula interdisciplinar e contextualizada com o ensino de programação, além de estimular as habilidades propostas para as crianças nessa faixa etária, conforme indicado na habilidade EF15AR10 da BNCC (2018) que orienta que os estudantes dessa faixa etária devem experimentar diferentes formas de orientação no espaço.

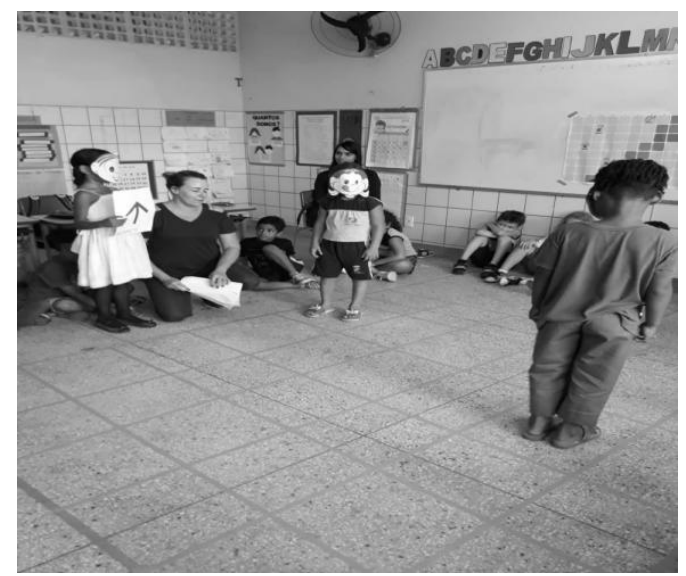

Figura 4. Jogo de tabuleiro no chão

Dentro do que foi proposto nas atividades anteriores, e relacionando ao que acredita Papert (1997, p.104), que afirma que as crianças podem aprender construindo, levantou-se questionamentos para impulsionar as crianças a pensar sobre os conceitos de programação associados aos comandos realizados com o corpo. Para melhor compreensão utilizamos a plataforma Hora do Código, criada pela organização não 
VIII Congresso Brasileiro de Informática na Educação (CBIE 2019)

Anais dos Workshops do VIII Congresso Brasileiro de Informática na Educação (WCBIE 2019)

governamental code.org, para desmistificar a programação e mostrar que qualquer pessoa pode aprender os fundamentos básicos e ampliar a participação na área desta ciência.

A atividade foi realizada na lousa digital, pois a escola não dispunha de computadores para todos os estudantes. Com a atividade foi possível observar na prática o que foi visto através das dinâmicas e explanações de forma desplugada, a turma de forma coletiva ajudava um colega na resolução dos desafios do jogo Angry Birds, a fim de escolher a sequência de instruções corretas para resolução do problema conforme a Figura 5.

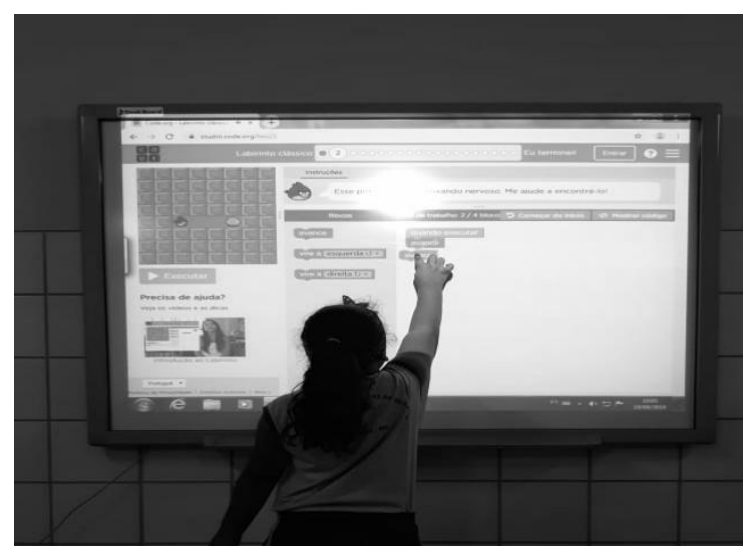

Figura 5. Atividade da Hora do Código na Lousa Digital

Além da solidificação dos conceitos de algoritmos e da importância de uma sequência lógica de passos para atingir um objetivo, a atividade colaborativa teve como objetivo desenvolver a interação do grupo, oportunizando mais estratégias com diferentes olhares para o mesmo ângulo. Isso é uma característica do pensamento computacional que coloca o raciocínio lógico para funcionar em diversas áreas. Seguindo essa ideia, Wing (2016, p. 04) afirma que:

\begin{abstract}
"Ao resolver um problema eficientemente, podemos questionar se uma solução aproximada é boa o suficiente e se falsos positivos ou falsos negativos são permitidos. O pensamento computacional é reformular um problema aparentemente difícil em um problema que sabemos como resolver, talvez por redução, incorporação, transformação ou simulação".
\end{abstract}

Ao final, a fim de avaliar a atividade, os alunos responderam algumas perguntas como: "Vocês gostaram da atividade?" e "Qual o tipo de jogo mais gostaram?". As respostas foram contabilizadas pelas professoras e os resultados podem observados no gráfico da figura 6. Observa-se que todos os alunos afirmam terem gostado da atividade e que a maioria da turma mostrou-se mais interessada na atividade do jogo digital, o que é explicado pelo atrativo dos gráficos e personagens computacionais do jogo online. 
VIII Congresso Brasileiro de Informática na Educação (CBIE 2019)

Anais dos Workshops do VIII Congresso Brasileiro de Informática na Educação (WCBIE 2019)

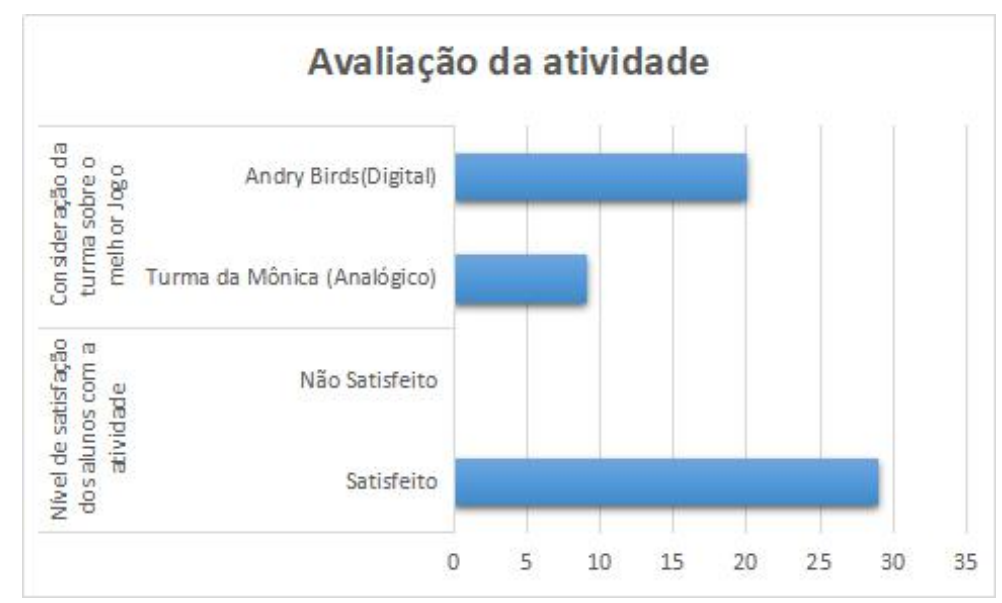

Figura 6. Percepção dos estudantes quanto à execução da atividade

Além disso, de forma subjetiva, os alunos foram questionados sobre quais foram as dificuldades para executar as tarefas e se consideravam que ocorreu aprendizado durante a atividade. Os estudantes relataram que a maior dificuldade foram os conceitos de direita e esquerda e afirmaram terem compreendido os conceitos durante a execução da tarefa. Desse modo, ficou acordado dar continuidade do desenvolvimento do pensamento computacional nas aulas seguintes através da Hora do Código na sala de informática e no jogo tabuleiro da Turma da Mônica, a fim de, solidificar tais conceitos.

\section{Considerações Finais}

A elaboração desta proposta consistiu em estabelecer estratégias e metodologias para introduzir o ensino de programação como uma maneira de agregar o uso da tecnologia ao ambiente escolar, proporcionando às crianças a oportunidade de estimular seu raciocínio lógico e sua localização espacial. Observou-se que a execução da atividade em grupo foi positivo para a socialização entre os pares e para construção do conhecimento de forma crítica.

Considera-se que dentro das atividades propostas e do perfil dos alunos, os objetivos de estimular o raciocínio lógico e a orientação espacial por meio de atividades desplugadas e jogos online foram alcançados. Porém, acredita-se que para realizar as atividades com crianças de idade e séries maiores é necessário ampliar as dificuldades e desafios, a fim de aguçar a curiosidade das crianças sobre o pensamento computacional, pois, embora os conceitos sejam os mesmos é preciso inserir de acordo com o nível adequado a cada fase.

Dessa forma, a pesquisa contribui para o entendimento de que é possível o ensino de programação para os alunos do Ensino Fundamental nas séries iniciais, na perspectiva de conhecimento científico, desenvolvendo habilidades específicas dentro das áreas de conhecimento. Portanto, a presente proposta pode ser replicada por outros professores, com possibilidades de adequação da estratégia, observando-se o contexto da turma. 
VIII Congresso Brasileiro de Informática na Educação (CBIE 2019)

Anais dos Workshops do VIII Congresso Brasileiro de Informática na Educação (WCBIE 2019)

\section{Referências}

Almeida, Maria Elizabeth Bianconcini; Valente, José Armando. (2014) “Tecnologias Digitais, Linguagens e Currículo: Investigação, Construção de Conhecimento e Produção de Narrativas".

Luckesi, Cipriano Carlos. (1992) "Avaliação da aprendizagem escolar: sendas percorridas." Tese (Doutorado em Filosofia da Educação) - Pontifícia Universidade Católica, Pontifícia Universidade Católica, São Paulo.

Brackmann, Christian. (2017) "Desenvolvimento do Pensamento Computacional Através de Atividades Desplugadas na Educação Básica." Universidade Federal do Rio Grande do Sul (UFRGS), Porto Alegre, RS, Brasil. Disponível em: $<$ http:/hdl.handle.net/10183/172208>

Bee, H. (1984) “A criança em desenvolvimento”. São Paulo, SP. Harper \& Row do Brasil Ltda.

BNCC. (2017) "Base Nacional Comum Curricular: educar é a base". Ministério da Educação, $3^{\circ}$ versão. Atualizada.

CIEB. (2019) "Referências para construção do seu currículo em tecnologia e computação da educação infantil ao ensino fundamental". Centro de Inovação para a Educação Brasileira. Disponível em: http://curriculo.cieb.net.br/. Acessado em 17 de setembro de 2019.

Gasparini, I.; Kemczinski, A.; Crema, C. (2018) "Pensamento Computacional no Ensino Fundamental I: um estudo de caso utilizando Computação Desplugada". Anais dos Workshops do CBIE 2018. Disponível em: https://brie.org/pub/index.php/wcbie/article/view/8294. Acessado em 20 de setembro de 2019.

Goulart, I.; Guarda, G. (2018) "Jogos Lúdicos sob a ótica do Pensamento Computacional: Experiências do Projeto Logicamente". Anais do XXIX Simpósio Brasileiro de Informática na Educação. Disponível em: https://brie.org/pub/index.php/sbie/article/view/8005. Acessado em 19 de setembro de 2019.

Papert, S. (1997) "A família em rede: ultrapassando a barreira digital entre gerações." Título original: The Connected Family: bridging the digital generation gap. Lisboa: Relógio D'Água Editores.

Sousa, D.; Souza, N.; Lima, A.; Silva, N. (2017) "Raciocínio Lógico nas Escolas: Uma Introdução ao Ensino de Algoritmos de Programação". Anais dos Workshops do CBIE 2017. Disponível em: https://br-ie.org/pub/index.php/wcbie/article/view/7490. Acessado em 21 de setembro de 2019.

Wing, J. (2016) "Pensamento computacional - Um conjunto de atitudes e habilidades que todos, não só cientistas da computação, ficaram ansiosos para aprender e usar". Revista brasileira Ensino Ciência Tecnologia, Ponta Grossa, v. 9, n. 2, p. 1-10. 